\title{
FEOCROMOCITOMA GIGANTE
}

\author{
A ngélica M aría Fonseca*, William Rojas M D**
}

\section{Resumen}

El feocromocitoma es una neoplasia neuroendocrina de células cromafines que biosintetiza, almacena, metaboliza y secreta concentraciones elevadas de catecolaminas y sus metabolitos. La incidencia es de dos a ocho casos por millón y es frecuente en la cuarta y quinta décadas de la vida. Presentación del caso: mujer de 19 años con cifras tensionales elevadas en controles médicos por antecedente de asma desde la niñez, que se estudia con análisis bioquímicos y TAC abdominal. Se llevó a cirugía ante la sospecha de un tumor adrenal y la neoplasia se caracteriza en el servicio de patología. Conclusiones: el diagnóstico de feocromocitoma y paragangliomas simpáticos que sintetizan y secretan catecolaminas (adrenalina, noradrenalina y dopamina) se basa en el examen físico y el estudio analítico; el principal síntoma es hipertensión arterial. El tratamiento es quirúrgico con curación completa en más del $\mathbf{9 0 \%}$.

Palabras clave: glandula suprarrenal, hipertensión arterial, paraganglioma, feocromocitoma.

Abreviaturas: FC, feocromocitoma(s); PG, paraganglioma(s).

\section{GIANT PHEOCHROMOCYTOMA}

\section{Abstract}

Pheochromocytomas are neuroendocrine cromaffin cell tumors which synthetize store, and secrete high concentrations of catecholamines and their metabolytes. Incidence is two to eight cases per million and they are most common in the fourth and fifth decades of life. Case report: a 19-year-old woman with high blood pressure levels in medical follow-ups for presenting asthma since her childhood. She is studied by biochemical analyses and abdominal CT scan. She undergoes surgery due to suspicion of an adrenal tumor and the surgical specimen is characterized in the pathology service. Conclusions: the diagnosis of pheochromocytoma and simpathetic paragangliomas which synthetize and secrete catecholamines (adrenaline, noradrenaline and dopamine) is based on physical exam and complete analyses; the main symptom is arterial hypertension. Surgery is the basis of therapy with complete healing in more than $90 \%$ of cases.

Key words: suprarenal gland, arterial hypertension, paraganglioma, pheochromocytoma.

Fecha recibido: julio 8 de 2014 - Fecha aceptado: octubre 16 de 2014

* Estudiante de medicina VI semestre. Fundación Universitaria de Ciencias de la Salud. Bogotá DC, Colombia.
** Jefe del Servicio de Endocrinología, Hospital de San José. Profesor Asociado, Fundación Universitaria de Ciencias de la Salud. Bogotá DC, Colombia. 


\section{Introduc ción}

Se define feocromocitoma como tumor benigno de células cromafines que biosintetizan, almacenan, metabolizan y secretan concentraciones el evadas de catecolaminas y sus metabolitos. La incidencia es de dos a ocho casos por cada millón de sujetos, es frecuente en la cuarta y quinta décadas de la vida. Su prevalencia en la población hipertensa es de 0.2 a $0.4 \%^{1}$, el 80 a $85 \%$ se localiza en la médula adrenal y el resto en el tejido cromafin extraadrenal (paraganglioma). ${ }^{2}$ Representa el $6,5 \%$ de los tumores incidentales de la suprarrenal. ${ }^{2} \mathrm{~A}$ fecta a ambos sexos de manera similar. Es raro en niños y cuando ocurre puede ser múltiple y asociado con síndromes hereditarios como neoplasia endocrina múltiple 2, enfermedad de Von Hippel-L indau, neurofibromatosis tipo 1 y paraganglioma familiar con mutaciones de la succinato deshidrogenasa. ${ }^{1}$

La triada clínica clásica consiste en cefalea (80\%), palpitaciones $(64 \%)$ y diaforesis $(57 \%)$, debido al aumento en la concentración de catecolaminas circulantes. La hipertensión resul tante puede ser mantenida en cerca de la mitad de los pacientes y paroxística en un tercio, mientras el resto cursa con normotensión. La regla del 10 ( $10 \%$ extraadrenales, $10 \%$ en niños, $10 \%$ múltiples o bilaterales, $10 \%$ recidivan tras la cirugía, 10\% son malignos, 10\% familiares y $10 \%$ descubiertos como incidentales adrenales) no es del todo cierta. Se debe sospechar en las siguientes situaciones: hipertensión resistente al tratamiento, crisis adrenérgicas, historia familiar de FC, síndrome genético que predisponga, imagen sugestiva de masa adrenal en la radiología, hipertensión en paciente joven y respuesta presora durante la inducción de anestesia. ${ }^{2}$

En cuanto al tratamiento, la cirugía no siempre conduce a la curacion de los pacientes, incluso en tumores benignos. Se han descrito recidivas en $16 \%$ de los pacientes, siendo más frecuente en jóvenes, enfermedad familiar, afección bilateral o extraadrenal y tumores localizados en la glandula suprarrenal derecha (62\% frente al $7 \%)^{2}$

\section{Presentación del caso}

M ujer de 19 años con cifras tensionales elevadas como hallazgo incidental en controles médicos por antecedente de asma desde la niñez y consumo de montelukast una tableta/día, beclometasona 2 puff cada 12 horas, sal butamol a necesidad como medicamento de rescate y amlodipino $5 \mathrm{mg} / \mathrm{dí}$. Como antecedentes familiares relevantes una abuela y padre con hipertensión arterial y una hermana con asma. Al examen no se registraron cifras tensionales altas. Se decide iniciar estudios endocrinológicos para investigar hipertensión de origen endocrino con base en anamnesis y antecedentes (Tabla 1).

EI TAC abdominal reportó lesión de aspecto redondeado de contornos definidos en relación con el polo superior del riñón izquierdo, realce 96 y 92 unidades

\begin{tabular}{|l|l|}
\multicolumn{2}{|c|}{$\begin{array}{c}\text { Tabla I. Resultados de exámenes paraclínicos } \\
\text { realizados a la paciente }\end{array}$} \\
\hline Paraclínicos & Resultados \\
\hline T4 libre & $1.4 \mathrm{ng} / \mathrm{dL}$ \\
\hline glicemia en ayunas & $63 \mathrm{mg} / \mathrm{dL}$ \\
\hline colesterol total & $252 \mathrm{mg} / \mathrm{dL}$ \\
\hline colesterol HDL & $60.2 \mathrm{mg} / \mathrm{dL}$ \\
\hline LDL & $174.4 \mathrm{mg} / \mathrm{dL}$ \\
\hline triglicéridos & $87 \mathrm{mg} / \mathrm{dL}$ \\
\hline creatinina & $0.7 \mathrm{mg} / \mathrm{dL}$ \\
\hline potasio & $4.3 \mathrm{mmol} / \mathrm{L}$ \\
\hline metanefrina libre en plasma & $\mathrm{menor} \mathrm{de} 25 \mathrm{pg} / \mathrm{mL}$ \\
\hline normetanefrina & $64 \mathrm{pg} / \mathrm{dL}$ \\
\hline metanefrinas totales & $64 \mathrm{pg} / \mathrm{mL}$ \\
\hline catecolaminas fraccionadas en orina/24h: \\
adrenalina & $4.2 \mathrm{ug} / 24 \mathrm{~h}$ \\
\hline noradrenalina & $24.22 \mathrm{ug} / 24 \mathrm{~h}$ \\
\hline metanefrinas & $0.26 \mathrm{mg} / 24 \mathrm{~h}$ \\
\hline dopamina & $242.20 \mathrm{ug} / 24 \mathrm{~h}$ \\
\hline cortisol & $229.2 \mathrm{nmol} / \mathrm{L}$ \\
\hline ácido vanilmandélico & $5.2 \mathrm{mg} / 24 \mathrm{~h}$ \\
\hline aldosterona & $307 \mathrm{pg} / \mathrm{mL}$ \\
\hline androsteneidona & $5.53 \mathrm{ng} / \mathrm{mL}$ \\
\hline dehidroandrosteneidona & $379.5 \mathrm{mcg} / \mathrm{dL}$ \\
\hline cortisol libre & $69.30 \mathrm{ng} / \mathrm{dL}$ \\
\hline
\end{tabular}


Hounsfield (UH) con áreas de necrosis de cerca de $68 \times 76 \mathrm{~mm}$, sin identificar la glándula suprarrenal izquierda, mientras la derecha no mostró al teraciones (Figura 1). Se llevó a cirugía y el procedimiento se adelantó sin complicaciones. En patología se recibe un nódulo encapsulado, pardo oscuro de $8 \times 7 \times 5 \mathrm{~cm}$, $178 \mathrm{gr}$ de peso y superficie de corte hemorrágica. A I estudio microscópico se observan células en nidos con núcleos ovalados y citoplasma eosinófilo granular fino y estructuras vasculares prominentes. L os controles revelan cifras tensionales normales $(120 / 80 \mathrm{~mm} \mathrm{Hg})$.

\section{Disc usión}

Para el diagnóstico del FC y los PG simpáticos es vital un buen examen físico y el estudio paraclínico adecuado. La prueba de oro es la medición de metanefrinas fraccionadas (metanefrina y normetanefrina) en plasma 0, si es imposible, en orina de 24 horas; la elevación los de metanefrinas cuatro veces por encima del rango de referencia de acuerdo con la edad del paciente se asocia con una probabilidad casi de $100 \%$ de que se trate de un tumor secretor de catecolaminas. ${ }^{3}$

En raras ocasiones secreta de preferencia dopamina, en estos casos deben determinarse además sus metabolitos: ácido homovanílico y metoxitiramina. También los niveles séricos de cromogranina $A$, una proteína presente en la matriz soluble de los gránulos cromafines que sirve de excelente marcador tumoral y ha demostrado su utilidad en el diagnóstico y seguimiento de estos y otros tumores de estirpe neuroendocrina. ${ }^{3}$

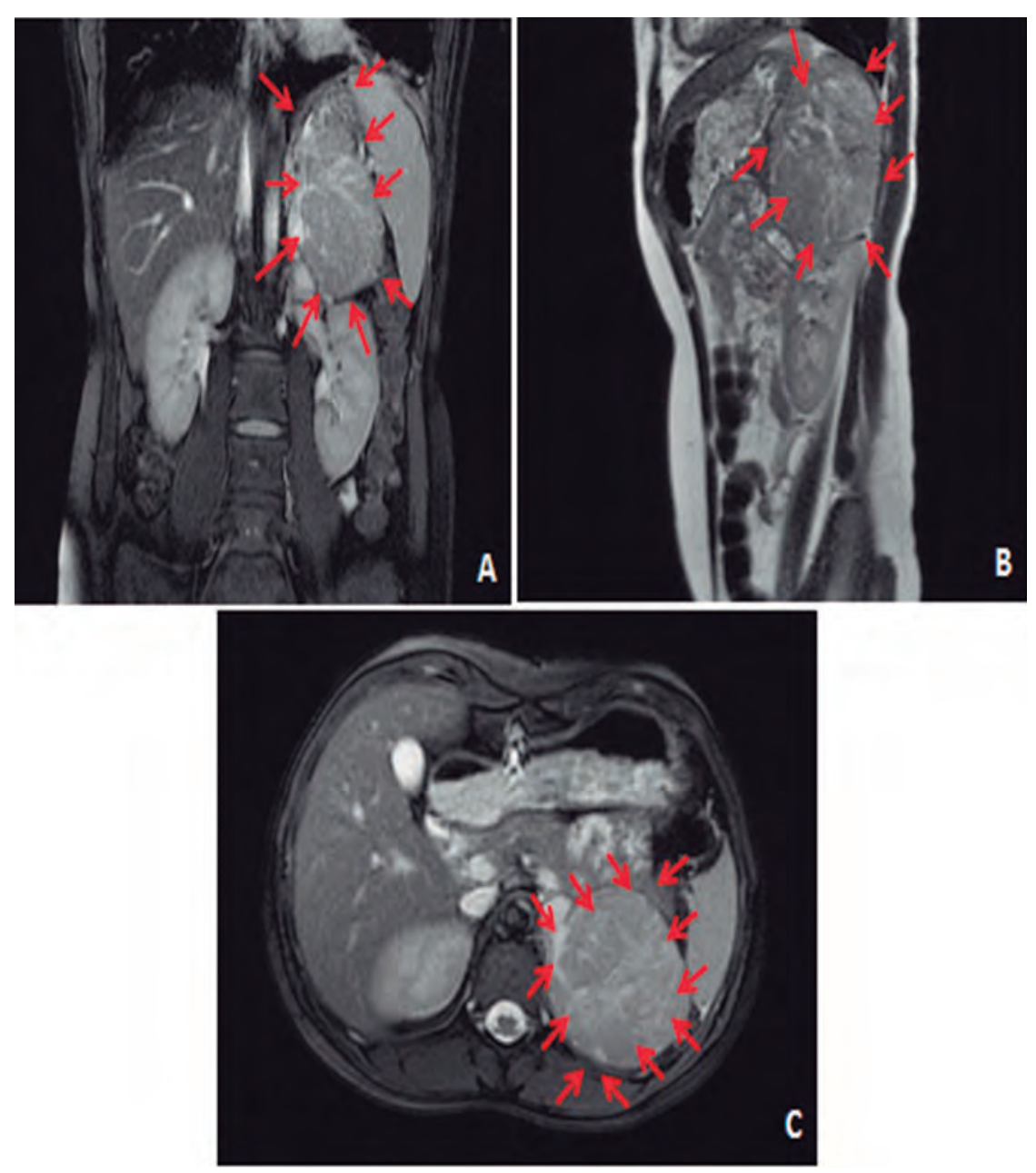

Figura I. Tomografía axial computarizada en tres cortes que muestra la masa; $\mathrm{A}$ corte coronal, B corte sagital y C corte transversal (las flechas indican la lesión). 
Establecida la evidencia bioquímica de un FC/PG, el tumor debe localizarse. Las pruebas de primera elección son TAC y resonancia magnética de abdomen y pelvis. Cuando el estudio es negativo se hará de tórax y cuello. Tienen una excelente sensi bilidad diagnóstica, pero su especificidad es baja. Para mejorarla se utilizan imágenes funcionales como la escintigrafía corporal total con metaiodobencilguanidina (M IBG) marcada con yodo. ${ }^{3}$ Se sabe que la prevalencia de adenomas adrenales aumenta con la edad, así la probabilidad de encontrar uno insospechado en un TAC abdominal en pacientes de 20 a 29 años es del 0,2\%, comparado con cerca de $7 \%$ en mayores de 70 años. ${ }^{4}$

El tratamiento es en esencia quirúrgico con curación completa en más del $90 \%$ de los casos. No obstante, conlleva al to riesgo cardiovascular debido a complicaciones prequirúrgicas como la liberación masiva de catecolaminas por inducción anestésica e intubación, las quirúrgicas por la manipulación del tumor causando crisis hipertensiva y hemorragia cerebral, caída brusca de catecolaminas tras el aislamiento (pinzamiento vascular) y extirpación del tumor, arritmias e infarto agudo de miocardio, y las posquirúrgicas como la hipotensión y choque secundarios a la hipovolemia previa. ${ }^{3}$

Con respecto a la presentación clínica es progresiva y larvada con incremento de las cifras tensionales y cefalea, para luego encontrar un tumor de $8 \times 7 \times 5$ $\mathrm{cm}$ de $178 \mathrm{~g}$ de manera incidental, hace que este hallazgo pertenezca a un gran grupo de tumores que tienen similar comportamiento clínico conocido como incidentalomas. Estos no son hipersecretores, y corresponden a adenomas adrenocorticales benignos. Otros diagnósticos reportados con frecuencia incluyen adenoma adrenocortical secretor de cortisol, FC, carcinoma adrenocortical y carcinoma metastásico; el FC solo equivale un $5 \%$ de este grupo de incidentalomas adrenales. ${ }^{4}$

Como parte del estudio diagnóstico se deben realizar estudios genéticos, porque según lo comentado pueden ser esporádicos o forman parte de un síndrome hereditario. De acuerdo con los últimos estudios sobre FC no sindrómico, aumenta alrededor de $24 \%$ la probabilidad de que puedan ser hereditarios. ${ }^{5}$ L os FC y PG productores de catecolaminas pueden ser causados por mutaciones de linea germinal en alguno de los cinco genes identificados a la fecha: el reorganizado durante la transfección (RET) del proto-oncogen, cuando las mutaciones llevan a la neoplasia endocrina multiple tipo 2 (M ET 2); el gen de von Hippel Lindau (V HL) en el que las mutaciones conducen al síndrome con este nombre; el gen de la neurofibromatosis tipo 1 (NF1) asociado con el sindrome de von Recklinghausen y los genes codificadores de las subunidades $B$ y D (SDHB y SDHD) de la succinato deshidrogenasa, las cuales se asocian con FC y PG no sindrómicos. ${ }^{5}$ $L$ as pruebas disponibles para los cuatro genes anteriores (RET, VHL, SDHD y SDHB) demuestran que las mutaciones en línea germinal son responsables del $10 \%$ de los tumores descritos como hereditarios ${ }^{5}$, con patrón autosómico dominante. ${ }^{6}$

Es importante recordar que entre 7,5 y $27,0 \%$ de los tumores sin un síndrome usual o historia familiar, resulta de manera insospechada en mutaciones de línea germinal de uno de estos cuatro genes. L a predisposición hereditaria para FC es de 20 a 30\%. La alta prevalencia de mutaciones insospechadas indican la necesidad de realizar pruebas genéticas más amplias ${ }^{5}$, porque la base genética de la mayoría de los FC esporádicos no se ha caracterizado. ${ }^{7} \mathrm{~L}$ as mutaciones somáticas en los genes involucrados en el FC hereditario ocurren muy poco en tumores esporádicos. Por el análisis de todo el genoma ahora aparece un nuevo locus en el cromosoma 2 que podría considerarse en al gunos casos restantes de FC familiar. ${ }^{7}$

Según en el Primer Simposio Internacional en Feocromocitoma se recomendó que no es apropiado ni costo efectivo realizar la prueba de cada gen causante de la enfermedad en todos los pacientes con esta patología. Para escoger la prueba genética adecuada deben evaluarse el perfil bioquímico de secreción de catecolaminas, edad del paciente, localización del tumor primario y antecedente familiar. Genes como MEN 2 y NF1 cursan con FC secretores de epinefrina, el gen VHL está relacionado siempre con FC secretores de norepinefrina y la elevación de dopamina junto con norepinefrina se ve en algunos PG relacionados con la mutación en el gen SD HB. L os tumores por mutación 
en genes MEN2, VHL y NF1 están en su mayoria en la glándula adrenal, mientras los relacionados con el gen SDHB son de localización extraadrenal. A I gunos estudios sugieren que cerca de dos tercios de los casos de FC o PG relacionados con el gen SDHB pueden desarrollar enfermedad metástasica. ${ }^{5}$

L a revisión realizada por Glodny en 2001 recomienda la detección temprana pues $90 \%$ de los FC son curables por medio de resección quirúrgica. A demás se ha reportado un aumento de la incidencia encontrando que $75 \%$ de todos los FC permanecen indetectables y $55 \%$ fueron la causa de muerte. ${ }^{8}$

L a tasa de mortalidad ha disminuido de $20 \%$ en 1951 a menos del $5 \%$ en la actualidad. La preparación farmacológica preoperatoria es un factor clave en la reducción de la mortalidad. El objetivo del tratamiento preoperatorio consiste en controlar la hipertensión y aumentar el volumen circulante. ${ }^{1}$

\section{Conclusión}

Para el diagnóstico del FC y PG simpáticos que sintetizan y secretan catecolaminas (adrenalina, noradrenalina, y dopamina) es importante el examen físico y el estudio analítico; entre los principales síntomas se encuentra la hipertensión arterial asociada con la triada clásica. Hay que recordar que la recurrencia 0 la presencia de otros tumores pueden estar asociadas con síndromes de carácter genético, remitiendo estos pacientes a la consejería respectiva como parte del manejo integral. En cuanto a los tumores esporádicos no hereditarios el tratamiento es en esencia quirúrgico, lo que permite la curación completa en más del $90 \%$ de los casos; sin embargo, la benignidad o malignidad del tumor depende del estudio histopatológico y a partir de éste se llevará a cabo el seguimiento y la implementación de otra clase de tratamientos como la quimioterapia.

\section{Referencias}

1. Posadas Calleja JG, U garte Torres A, Dominguez Cherit G. Feocromocitoma. Experiencia de 15 años en una instituciñn mexicana. M ed Int M ex. 2006; 22(3): 210-15.

2. Oleaga A, Goñi F. Feocromocitoma: actualizacion diagnostica y terapeutica. Endocrinol Nutr. 2008; 55(5):202-16.

3. M artos-M oreno G, Pozo-Román J, A rgente J. Tumores suprarrenales en la infancia. An Pediatr. 2013; 79(3): 187.e1-187.e16.

4. Young WF J r. Clinical practice. The incidentally discovered adrenal mass. N Engl J M ed. 2007; 356(6):601-10

5. Pacak K, Eisenhofer G, Ahlman H, Bornstein SR, Gimenez-Roqueplo AP, Grossman AB, et al. Pheochromocytoma: recommendations for clinical practice from the First International Symposium. October 2005. Nat Clin Pract Endocrinol M etab. 2007; 3(2):92-102.

6. Chen H, Sippel R, O'Dorisio M, Vinik A, Lloyd R, Pacak K, et al. The North A merican N euroendocrine Tumor Society consensus guideline for the diagnosis and management of neuroendocrine tumors: pheochromocytoma, paraganglioma, and medullary thyroid cancer. Pancreas. 2010; 39(6):775-83.

7. Eisenhofer G, Bornstein SR, B rouwers FM, Cheung NK, Dahia PL, de K rijger $R R$, et al. M alignant pheochromocytoma: current status and initiatives for future progress. Endocr Relat Cancer. 2004; 11(3):423-36.

8. Glodny B, Winde G, Herwig R, Meier A, K"uhle C, Cromme S et al. Clinical differences between benign and malignant pheochromocytomas. Endocr J. 2001; 48(2):151-9. 